\title{
Donald Trump: a resposta norte-americana aos efeitos desestabilizadores da globalização do capital
}

\author{
Donald Trump: the American response \\ to the destabilizing effects of the globalization of capital
}

Corival Alves do Carmo ${ }^{1}$

Resumo: O processo de integração da economia mundial liderado pelos Estados Unidos gerou efeitos dúbios para o país. Enquanto, as empresas norteamericanas ampliaram a presença e o domínio sobre a economia mundial, houve uma deterioração do mercado de trabalho nos EUA e das condições de vida da classe média, o que gerou um ressentimento em relação à Wall Street depois da crise de 2008 e também questionamentos sobre os benefícios da inserção na economia mundial para os EUA. O objetivo do artigo, então, é analisar como esse contexto favoreceu a ascensão de Trump e suas propostas para rever algumas das características do liberalismo que pautaram a política econômica externa dos EUA desde o final da Segunda Guerra Mundial.

Palavras-chave: Trump, declínio norte-americano, ascensão da China.

Abstract: The process of integrating the world economy led by the United States has had dubious effects on the country. While US corporations expanded their presence and dominance over the world economy, there was a deterioration of the US labor market and middle-class living conditions, which generated resentment of Wall Street after the crisis of 2008 and also questions about the benefits of insertion into the world economy for the US. The purpose of this paper is to examine how this context favored Trump's rise and his proposals to review some of the characteristics of liberalism that guided US foreign policy since the end of World War II.

Keywords: Trump, US decline, China's rise.

(c) EY Direito autoral e licença de uso: Este artigo está licenciado sob uma Licença Creative Commons. Com essa licença você pode compartilhar, adaptar, para qualquer fim, desde que atribua a autoria da obra, forneça um link para a licença, e indicar se foram feitas alterações. 


\section{Introdução}

As eleições de 2016 nos Estados Unidos evidenciaram as contradições presentes no processo de globalização do capital e as tensões sociais e políticas daí decorrentes. A partir de espectros políticos bastante distintos, tanto Bernie Sanders como Donald Trump buscaram apoio nos setores marginalizados pelo processo de internacionalização do capital norte-americano e pela integração capitalista em escala mundial e tentaram colocar em Hillary Clinton a pecha de representante dos interesses da elite globalista. A liberalização e a desregulamentação comerciais e financeiras em escala global desde os anos 1970 promoveram uma reorganização das cadeias produtivas mundiais alterando os loci dos processos industriais, o direcionamento dos fluxos comerciais e aumentaram a escala e o papel da acumulação financeira.

Os Estados Unidos são o epicentro de onde se desencadeiam esses processos, que de um lado, reforçaram a posição do país como emissor da moeda, centro financeiro e tecnológico, e, de outro, permitiram um enfraquecimento relativo do setor industrial com o deslocamento do capital para a Ásia e o México, que acabam por alterar a estrutura do comércio internacional. O resultado é uma divisão dentro dos Estados Unidos entre os setores econômicos mais fortemente vinculados às bases econômicas nacionais e pouco competitivos internacionalmente, e os setores articulados globalmente, que tem por referência o mercado mundial. Se esta divisão causa tensões e conflito no âmbito empresarial gerando demandas políticas bastante divergentes, o efeito sobre a sociedade é ainda mais complexo ao aprofundar a desigualdade de renda entre os trabalhadores dos setores dinâmicos e internacionalizados e os setores de menor competitividade internacional e baixa produtividade. Ainda quando o desemprego seja baixo, a qualidade dos empregos se deterioraram em função das oscilações de salários, jornadas de trabalho, entre outros.

Donald Trump obviamente não faz parte dos perdedores da globalização nem como indivíduo nem pelas suas atividades empresariais. Entretanto, foi capaz de incorporar o discurso crítico e nacionalista em relação ao processo de globalização para alavancar sua carreira política. A posição política e econômica de Trump é bastante contraditória, converge com a posição tradicional do Partido Republicano em relação à demanda por redução de impostos, mas defende o aumento dos investimentos governamentais em infraestrutura, e é crítico dos processos de liberalização comercial por entender que os Estados Unidos estão perdendo neste processo ao abrir o seu mercado aos concorrentes estrangeiros e não haver a reciprocidade esperada por parte dos parceiros. A falta de coerência interna no discurso de Trump dificulta suas relações com o Partido Republicano, mas coloca obstáculos também para a operacionalização de suas propostas, e para que seu governo alcance resultados internos satisfatórios.

Nesse sentido, a presidência de Trump deve aumentar a instabilidade econômica e financeira internacional, porque as dificuldades para se definir o 
papel dos Estados Unidos na governança e estabilização da economia mundial devem aumentar já que não há mais nem o consenso sobre a linha liberalizante e institucionalista adotada pelos Estados Unidos desde o final da Guerra Fria em relação à agenda econômica e financeira internacional. Para o desenvolvimento do argumento, o artigo se dividirá em três partes além desta introdução e da conclusão. Na primeira indicaremos como as propostas do candidato Trump procuram redefinir o papel dos Estados Unidos na economia mundial. $\mathrm{Na}$ segunda serão abordadas as medidas adotadas por Trump até meados de julho de 2017 e as dificuldades enfrentadas para operacionalizar sua agenda. E, na terceira, trataremos das possíveis implicações.

O significado da candidatura Trump e suas propostas econômicas

A percepção sobre o declínio relativo dos Estados Unidos não é um fenômeno novo, desde o fim da conversibilidade do dólar em ouro em 1971 que pôs fim ao sistema de Bretton Woods, houve reiterados ciclos de discursos declinistas. Ao longo dos anos 1970, a instabilidade nas taxas de câmbio internacionais gerou um crescimento da demanda pelo marco alemão e o iene japonês, que num contexto de baixo crescimento do PIB e inflação elevada nos Estados Unidos, alimentaram o discurso sobre o declínio da hegemonia norte-americana no Ocidente ainda no contexto da Guerra Fria. O aumento da taxa de juros norte-americana no final dos anos 1970 e a chegada de Ronald Reagan (1981-1989) ao poder reafirmaram o poder dos Estados Unidos do ponto de vista monetária e financeiro e militarmente.

Entretanto, em meados dos anos 1980, o discurso sobre o declínio dos Estados Unidos ganha novamente apelo midiático em função das crescentes compras de empresas norte-americanas por empresas japonesas, pelos resultados excepcionais da indústria automobilística japonesa em comparação com a norte-americana. De modo geral, as empresas norte-americanas pareciam estar em desvantagem na competição com o modelo japonês. Os Estados Unidos reagem demandando revisão das políticas comerciais do Japão e dos novos países industrializados. Paralelamente às negociações multilaterais da Rodada Uruguai do GATT, os Estados Unidos tomam várias decisões unilaterais para pressionar pela alteração nas políticas comerciais dos concorrentes.

As duras negociações comerciais com o Japão marcam o final dos anos 1980 e início dos anos 1990. Quando as negociações se concluem no primeiro mandato de Bill Clinton (1993-2001), tanto no nível bilateral quanto no multilateral com a criação da OMC, o cenário já havia se modificado, o Japão já estava em crise, a Alemanha enfrentava o desafio da reunificação, a União Soviética havia chegado ao fim, e os Estados Unidos apareciam como o vencedor da Guerra Fria e o construtor de uma nova ordem internacional. A segunda metade dos anos 1990 foi marcada pelo elevado crescimento econômico e pela retomada da liderança tecnológica dos Estados Unidos 
evidenciada na bolha financeira em torno das empresas de tecnologia de informação e da internet.

Os efeitos do estouro da bolha financeira em 2001 seriam sentidos ao mesmo tempo em que as consequências dos ataques terroristas de 11 de setembro. A reação norte-americana liderada por George W. Bush (2001-2009) aos ataques terroristas com os ataques ao Afeganistão e ao Iraque parece apontar para a reafirmação do poder americano diante da demonstração de fragilidade e insegurança que o sucesso dos ataques teria indicado. A crise financeira de 2008 e os resultados econômicos alcançados pela China e por outros países emergentes trazem novamente à tona o debate sobre o declínio dos Estados Unidos.

Apesar da origem da crise econômica ser a estrutura financeira interna dos Estados Unidos, os efeitos negativos passam a ser subjetivamente associados a crescente presença chinesa na economia mundial já que a China não sofre os efeitos da crise norte-americana na mesma escala que outras regiões e países do mundo. Ao contrário, o poder econômico chinês cresce, a China aumenta sua participação no comércio mundial, tornando o maior exportador mundial, e o principal parceiro comercial da maior parte dos países do mundo além de ter incrementado o superávit comercial em relação aos Estados Unidos.

A China ocupa agora o papel anteriormente ocupado pelo Japão, o de desafiante do poder norte-americano, com um agravante adicional, a possibilidade de desafiar também do ponto de vista político-militar e não apenas através da concorrência econômica, apesar de essa ser a mais destacada publicamente. Peter Navarro, atualmente diretor do Conselho Nacional de Comércio criado pelo presidente Trump, é um dos principais difusores do discurso sobre a ameaça representada pela China para a economia norteamericana. Navarro publicou, ainda em 2006, o livro "The coming China wars: where they will be fought, how they can be won", em 2011, publicou o livro "Death by China" e no ano seguinte um documentário com o mesmo título. A concorrência econômica com a China é abordada por Navarro em termos militares, e no documentário, esse aspecto aparece bastante ilustrado com as imagens. Mas a China não é o único inimigo, o documentário de Navarro aponta as grandes companhias multinacionais de origem norte-americana como não tendo mais compromissos com os interesses nacionais do país seja por privilegiarem seus interesses econômicos no exterior e inclusive sendo dirigidas por estrangeiros ${ }^{2}$. A série de Navarro lançada em 2015, "Crouching Tiger: what China's militarism means for the world", enfatiza ainda os aspectos militares da ameaça chinesa, Navarro entende que um confronto com a China é inevitável para os Estados Unidos.

Peter Navarro disputou algumas eleições ao longo dos anos 1990 pelo partido Democrata e se define como "a Reagan-Trump Democrat abandoned long ago by my party on the economy, trade and foreign policy"3. A definição 
reflete como a sua visão é marginal em relação ao establishment político norteamericano nos dois partidos, e como a sua ascensão expressa o reordenamento ideológico promovido por Trump a partir da busca de uma reação à decadência dos Estados Unidos, "Make America Great Again". As ideias de Navarro sobre economia, e especialmente sobre a dinâmica do comércio internacional, distanciam bastante das concepções liberais dominantes desde o final da Segunda Guerra Mundial em versões mais ou menos radicais.

Os títulos de reportagens sobre ele publicadas após sua nomeação por Trump mostram a distância entre suas ideias e o establishment acadêmico, político e econômico. Artigo de Heilbrunn no Politico foi intitulado "The most dangerous man in Trump world? How Peter Navarro could lead us into a global depression - or worse"4; Williamson na National Review publicou o artigo "Peter Navarro: Trump's nutty economics professor"; ; na Forbes, Tim Worstall colocou como título "Trump admin's Peter Navarro doesn't know Econ 101 about trade" ", Econ 101 refere-se ao curso de introdução à economia da maioria das universidades norte-americanas.

De fato, para capturar o sentimento difuso de insatisfação com os rumos da economia e da sociedade norte-americanas não é possível apresentar uma proposta política e econômica coerente do ponto de vista teórico e programático, é preciso um discurso que se adapte a diferentes estratos da população. As propostas e a atuação política de Trump têm recebido o rótulo de populismo pelos seus críticos. O termo populismo é plurissemântico e adapta-se a diferentes contextos políticos. Theodore Roosevelt foi associado ao populismo especialmente nas eleições de 1912, o movimento dos Narodniks no final do século XIX na Rússia é tratado como o populismo russo, os governos de Getúlio Vargas, Juscelino Kubitschek, Jânio Quadros e João Goulart no Brasil, e de Juan Domingo Perón na Argentina são tratados como populistas. A partir dos anos 1990, generalizou-se o uso pelas organizações internacionais e economistas ortodoxos do termo populismo para designar governos que não seguem as políticas econômicas ortodoxas, especialmente a de manutenção do superávit primário. O uso no caso da campanha pelo Brexit e de Trump a presidência associa-se a visão de que os políticos estão tentando mobilizar o sentimento de frustração dos indivíduos com diferentes aspectos de suas vidas para obter ganhos eleitorais.

Apesar da recuperação da economia nos últimos anos do governo Obama, a campanha de Trump enfatizou o grande número de desempregados, e o baixo crescimento da economia, e a desindustrialização causada pelo deslocamento de várias indústrias para o exterior. Na apresentação das propostas econômicas, "Outline of Donald Trump's economic vision: winning the global competition", enfatiza-se os elementos anteriores e o aumento da pobreza em Detroit para indicar o objetivo da política econômica durante seu governo, "all economic policy must be geared towards making it easier to hire, invest, build, 
grow and produce in America - creating a level playing field for our workers and businesses in global competition, and creating Jobs here, not overseas"7.

Ou seja, a economia mundial é entendida como um jogo de soma zero e as questões econômicas são apresentadas como uma disputa entre os norte-americanos e o resto do mundo. Generaliza-se, portanto, para o mundo a concepção apresentada por Navarro a partir das disputas comerciais com a China. E, se os investimentos das empresas multinacionais norte-americanas no exterior são vistos como contrário aos interesses norte-americanos, confrontase a visão de mundo dominante desde o final da Segunda Guerra Mundial. Se antes a esquerda na América Latina entendia que as empresas multinacionais eram o braço estendido do poder norte-americano na região, agora uma parcela da direita norte-americana entende que as empresas multinacionais são uma ameaça aos Estados Unidos.

Qual a causa da desvantagem norte-americana? Nesse aspecto, reiterase o discurso tradicional dos republicanos, impostos elevados e regulação excessiva. Obviamente a solução passa pela reversão desses aspectos, e também por celebrar acordos comerciais justos, que coloquem os interesses da "América" em primeiro lugar. Em termos de alterações tributárias, Trump prometeu fazer a maior reforma desde o governo Reagan, simplificando o sistema, reduzindo as faixas do imposto de renda de 7 para 3, criando novas isenções, limitando os impostos sobre qualquer negócio em 15\%, entre outras medidas para reverter as políticas de Obama e tornar os Estados Unidos o local mais atrativo para os investimentos.

O excesso de regulação custaria ao país dois trilhões de dólares ao ano, sendo, portanto, necessário alterar o marco regulatório. Entre as reformas, propunha uma moratória regulatória sobre novas normas das agências reguladoras, avaliação e revisão das normas vigentes para eliminar as que não forem essencialmente necessárias; "remover os burocratas que sabem apenas como eliminar empregos; substituí-los por especialistas que sabem como criar empregos"; rever "The Environmental Protection Agency's Clean Power Plan", que obriga o investimento em energias renováveis, "The EPA's Waters of the United States rule", "The Department of Interior's moratorium on coal mining permits" .

Além disso, as propostas relativas à reforma energética também são entendidas como um meio de estimular o crescimento através do barateamento do custo da energia, incluindo entre elas a saída do Acordo de Paris sobre Clima, a facilitação dos investimentos em petróleo, gás natural, gasodutos e oleodutos. Os objetivos econômicos e energéticos de curto prazo devem ter precedência em relação às medidas visando reduzir os fatores que afetam as características climáticas da Terra no longo prazo. No livro publicado em 2015, intitulado "Crippled America", e traduzido no Brasil como "Grande outra vez: como recuperar a América debilitada", Trump escreve: 
Em seu discurso State of the Union de 2015, o presidente Obama declarou que a maior ameaça ao planeta hoje em dia é a mudança climática. Maior ameaça?! Temos tropas do Estado Islâmico decepando cabeças de inocentes missionários cristãos. Temos uma coalizão de adversários na Síria apoiando um ditador que usa armas químicas contra seu próprio povo. Temos milhões de americanos com hipotecas superiores ao valor de sua propriedade, enquanto a renda da classe média está estagnada e mais de 40 milhões de cidadãos vivem na linha da pobreza. ${ }^{9}$

Em relação ao comércio exterior, o objetivo geral dos Estados Unidos nas negociações relativas ao comércio internacional deve ser buscar a redução do déficit comercial, aumentar a produção domésticas e alcançar acordos comerciais que sejam justos com os trabalhadores norte-americanos. E é preciso rever o que já foi feito, encerrar a participação norte-americana no Acordo Transpacífico, e renegociar o Nafta. A China aparece como um dos grandes vilões em função da manipulação da taxa de câmbio para influenciar nos resultados comerciais.

Mas as propostas indicam a necessidade de impor restrições a qualquer país que tentar manipular o comércio internacional em seu favor, e usar todos os instrumentos legais para responder às violações comerciais. Espera-se que a alteração nas políticas comerciais reverta em geração de emprego já que os acordos de liberalização seriam a causa da redução da oferta de emprego nos Estados Unidos. A saída do TPP evitaria um aumento de 23 bilhões de dólares no déficit comercial em automóveis até 2025.

O texto programático se encerra estabelecendo um contraste com a então candidata Hillary Clinton, e um dos pontos afirma "Hillary Clinton is a globalist, supporting almost every major job-killing trade deal" ${ }^{\prime}$. Trump escreveu:

Precisamos de uma legislação que dê às empresas americanas isenções fiscais e suporte financeiro para criar mais tecnologia e redirecionar mais de sua produção para o ambiente doméstico.

Devemos impedir que certos países desvalorizem suas moedas sem pensar duas vezes.

Somos o time da casa e devemos ter prioridade. (...)

Precisamos retomar empregos de países como China, Japão e México. Temos de nos posicionar e ser duros. Sob vários e excessivos aspectos estamos cedendo o maior mercado mundial - os consumidores americanos. ${ }^{11}$

Independente da avaliação sobre a candidatura de Clinton e sobre os acordos comerciais, o diagnóstico de Trump e de seu entorno sobre as 
repercussões das transformações da economia mundial sobre a economia dos Estados Unidos revela uma visão equivocada sobre a estrutura produtiva mundial atual. Os efeitos da liberalização promovida desde os anos 1970 já se consolidaram em cadeias produtivas integradas em escala mundial, a capacidade das grandes corporações de organizarem a sua produção em função do mercado mundial foi amplificada. O resultado é que mesmo os Estados Unidos enfrentariam grandes problemas se tentassem se desvincular dessa rede produtiva para tentar forçar a ampliação dos investimentos dentro do território norte-americano.

De fato, os Estados Unidos permanecem como o centro do desenvolvimento tecnológico, e isto também contra a geração de empregos, pois as indústrias instaladas nos Estados Unidos são cada vez mais intensivas em tecnologia; por outro lado, em termos da estrutura industrial e do comércio internacional estão sendo colocados cada vez mais na posição de mercado consumidor do resto do mundo como aponta Trump. Entretanto, não exatamente pelas suas debilidades, mas por seu poder financeiro. Neste aspecto, as propostas de Trump não conseguem avançar na direção de reequilibrar os diferentes papéis desempenhados pelos Estados Unidos na economia mundial. A avaliação de Dani Rodrik, um crítico da trajetória assumida pelo processo de globalização, é ainda mais ácida:

Today's consensus concerning the need to compensate globalization's losers presumes that the winners are motivated by enlightened self-interest - that they believe buy-in from the losers is essential to maintain economic openness. Trump's presidency has revealed an alternative perspective: globalization, at least as currently construed, tilts the balance of political power toward those with the skills and assets to benefit from openness, undermining whatever organized influence the losers might have had in the first place. Inchoate discontent about globalization, Trump has shown, can easily be channeled to serve an altogether different agenda, more in line with elites' interests. $^{12}$

\section{Os primeiros meses do governo Trump}

Milton e Rose Friedman (1983) analisaram o início do governo Reagan em “Tirania do Status Quo", e criticaram por não implementar imediatamente as propostas de mudanças econômicas defendidas na campanha ${ }^{13}$. Para os autores, Reagan havia perdido a janela de oportunidade existente nos seis primeiros meses de governo para introduzir mudanças com menor resistência do establishment político em função dos resultados eleitorais ainda terem força mobilizadora. Quanto mais o tempo passa, mais a agenda política e 
econômica passa ser influenciada pelas eleições legislativas no meio do mandato presidencial e pela própria campanha de reeleição. E no segundo mandato, o presidente já não teria a mesma capacidade de impor mudanças significativas. Enfim, Reagan estava sendo insuficientemente liberal e não teria muito como retomar a iniciativa de acordo com os autores.

As circunstâncias do início do governo Trump parecem mais difíceis, a fragmentação do partido Republicano, e o fortalecimento dos setores mais radicais em relação à demanda por redução da intervenção estatal associados à pequena vantagem numérica dos republicanos em relação aos democratas forçam a realização de negociações que não cabem nem dentro do discurso radical de Trump nem de sua experiência no setor privado. Como visto, o discurso de Trump durante a campanha fez uma composição entre propostas ultraliberais, conservadoras e nacionalistas. A implementação dessa agenda contraditória é um desafio, porque não se pode contar com o apoio dos mesmos grupos políticos na operacionalização das mesmas.

Ao longo da campanha, Trump criticou o suposto conformismo de Obama e Hillary Clinton com taxas de crescimento de $2 \%$, e prometeu em vários momentos elevar o crescimento para $5 \%$. No governo, estabeleceu inicialmente um objetivo mais realista, $3 \%$. Note-se que induzir uma trajetória de crescimento de 5\% em uma economia grande, complexa e madura como os Estados Unidos, é muito difícil, seria necessário mobilizar um volume de recursos extraordinariamente grande para elevar o nível de investimentos o que aumentaria ainda mais os já elevados: déficit público, dívida pública e déficit em transações correntes.

Dentro da retórica ultraliberal, a revogação do Obamacare foi a principal proposta endossada. Dentro os países desenvolvidos, os Estados Unidos notabilizavam-se por não ter um sistema público de saúde de acesso universal, a aprovação, em 2010, da Lei de Proteção e Cuidado Acessível ao Paciente (Patient Protection and Affordable Care Act), popularmente conhecida como Obamacare, representou uma importante inflexão nessa situação especialmente considerando o momento em que ocorreu, quase 30 anos depois do início do ciclo de liberalização e desregulamentação nos Estados Unidos e na União Europeia. Apesar de não alterar o sistema centrado em planos privados de saúde, as mudanças de Obama ampliaram significativamente o acesso ao sistema de saúde proibindo as seguradoras de recusar com pessoas com histórico prévio de doenças ou outros critérios estabelecidos pelas empresas, também ampliou os subsídios permitindo a inclusão de mais pessoas no Medicaid, obrigando as empresas com mais de 50 funcionários garanta planos de saúde aos mesmo ou paguem multa, obrigatoriedade de cadastramento em algum plano de saúde sob pena de multa.

Essas medidas representam uma intervenção no mercado e na liberdade individual, e desta perspectiva, é a causa do encarecimento dos preços dos 
seguros de saúde e do aumento do gasto público. Desde que tomou posse, Trump busca a revogação do Obamacare, entretanto, como não há consenso dentro do partido Republicano sobre o que colocar no lugar do programa, mesmo tendo maioria nas duas casas, o governo vem encontrado dificuldades para revogar ou alterar o sistema de saúde criado no governo Obama. Os setores mais liberais querem a simples revogação e os moderados do partido Republicano temem perder votos ao simplesmente revogar medidas que ampliaram o acesso à saúde. Um novo modelo foi aprovado na Câmara de Representantes depois de vários percalços e encontra muitas dificuldades na tramitação no Senado ${ }^{14}$.

Um dos compromissos assumidos por Trump para os primeiros 100 foi que para cada nova norma criada pela administração federal, duas normas antigas seriam revogadas visando a desregulamentação e a simplificação da legislação em diferentes setores. Apesar de ordem executiva ter sido baixada com essa determinação, a implementação é mais difícil pela necessidade de revisar os milhares de normas da administração federal para definir quais podem e devem ser revogadas ${ }^{15}$.

As mudanças mais notórias são as alterações nas posturas da administração norte-americana em relação às questões ambientais. Além da saída do acordo de Paris, a gestão de Trump já permitiu a retomada da construção de oleodutos em áreas com risco ambiental e reservas indígenas ${ }^{16}$. De um modo geral, Trump já deixou claro que durante a sua administração a prioridade em termos energéticos será a produção de petróleo, gás, carvão e xisto nos Estados Unidos, e, para tanto, as exigências legais relativas às energias limpas serão paulatinamente alteradas. Independentemente do retrocesso óbvio em termos ambientais, outras consequências são esperadas mesmo que os resultados esperados Trump em termos de emprego e crescimento sejam alcançados, o que em si mesmo é questionável. Em primeiro lugar, a queda do preço do petróleo e do gás deve se acentuar se a produção norte-americana crescer significativamente, o que ampliaria a instabilidade política e econômica nos países produtores de petróleo na periferia do mundo. Outro aspecto a ser observado, a China, apesar dos atuais níveis de poluição e consumo de energia convencional serem altos, tem tomado a dianteira em investimentos na geração e desenvolvimento de energias renováveis, a opção do governo Trump deve abrir maiores oportunidades para a China liderar o setor, e, portanto, lucrar com as novas oportunidades de negócio geradas pelas políticas de sustentabilidade ambiental. Ou seja, pode ser uma política que torne os Estados Unidos defasados econômica e tecnologicamente em relação ao principal concorrente no sistema internacional.

Dado o gosto pela provocação e a defesa de ideias radicais, algumas ideias defendidas por Trump durante a campanha chocaram os especialistas, mas devem ser entendidas apenas como provocação, retórica, por exemplo, a defesa do retorno do padrão ouro ${ }^{17}$. Outras temáticas devem ser acompanhadas 
pelo efeito mesmo de alterações moderadas. Um dos fatores críticos a serem acompanhados pelos seus efeitos internacionais é em que medida o governo Trump buscará alterar o Dodd-Frank Wall Street Reform and Consumer Protection Act, aprovado como resposta à crise de 2008 visando aumentar o controle sobre o sistema bancário e reduzir os fatores de risco sistêmico. A lei não alterou essencialmente o sistema, mas a sua revogação ou alteração profunda como indicado por Trump durante a campanha representaria uma abertura a um novo round de inovações financeiras e financeirização da riqueza.

Trump já pode fazer três nomeações para o FED (Federal Reserve) no momento, e poderá escolher substituir a presidente do FED, Janet Yellen, em 2018. A primeira indicação já foi feita no início de julho de 2017, Randal Quarles foi indicado para a área de regulação bancária. Além de ter atuado na Secretaria do Tesouro no governo de George W. Bush e sido diretor do FMI, Quarles é sócio de um fundo de investimento, e é visto como conservador em questões econômicas e um crítico da lei Dodd-Frank. Considerando que será o responsável pela supervisão do cumprimento das regulamentações pelos bancos, a nomeação parece sinalizar a disposição da administração Trump de retirar algumas das restrições que foram colocadas para limitar a atuação dos bancos e a sua disposição em assumir maiores riscos nas operações financeiras. A nomeação foi apresentada, então, pela mídia norte-americana como uma sinalização positiva para Wall Street ${ }^{18}$.

Além da retomada da desregulamentação bancária, Trump colocou nomes com projetos extremamente conservadores em termos econômicos. Mick Mulvaney, diretor de orçamento, por exemplo, defende o fim dos dois mandatos do FED. De acordo com a lei, o banco central norte-americano tem dois objetivos, buscar o nível máximo de emprego e manter a inflação estável. Mulvaney e outros do círculo de Trump, o próprio vice-presidente Mike Pence entre eles, defendem que o objetivo de reduzir o desemprego deve ser revogado, porque há situações em que os dois objetivos são contraditórios e a prioridade deve ser o controle da inflação. Outra proposta em relação ao FED que circula entre os economistas ligados ao governo é o estabelecimento de uma regra para definir a taxa de juros para acabar com o poder discricionário do comitê de de política monetária para definir as taxas de juros ${ }^{19}$.

Uma das propostas mais polêmicas colocadas por Trump durante a campanha em relação às questões econômicas foi aumentar a investigação e o controle sobre o FED. O próprio Trump ainda não liderou explicitamente nenhuma iniciativa nessa direção, mas um comitê da Câmara dos Representantes aprovou uma proposta de lei para aprovar uma investigação pelo Congresso da política Monetária adotada pelo $\mathrm{FED}^{20}$. A aprovação de medida desta natureza contrariaria completamente o tradicional modelo norte-americano de independência do banco central, e, ao mesmo tempo, se afastaria da teoria 
econômica neoclássica, base das práticas de política econômica dos Estados Unidos.

A página oficial da Casa Branca traz as principais questões tratadas pela administração Trump. Dentro da rubrica "America First Foreign Policy", pode-se ler:

For too long, Americans have been forced to accept trade deals that put the interests of insiders and the Washington elite over the hard-working men and women of this country. As a result, blue-collar towns and cities have watched their factories close and good-paying jobs move overseas, while Americans face a mounting trade deficit and a devastated manufacturing base. (...)

To carry out his strategy, the President is appointing the toughest and smartest to his trade team, ensuring that Americans have the best negotiators possible. For too long, trade deals have been negotiated by, and for, members of the Washington establishment. President Trump will ensure that on his watch, trade policies will be implemented by and for the people, and will put America first. ${ }^{21}$

Em relação ao comércio internacional, Trump ficou no meio do caminho entre a introdução de mudanças e a manutenção do status quo. Já cumpriu a promessa de abandonar as negociações sobre o acordo Transpacífico. Entretanto, abandonou a retórica de campanha em relação à China. Uma das promessas dos primeiros cem dias era rotular a China como "currency manipulator", apesar de ser uma promessa meramente retórica de fácil cumprimento, não foi adotada, e Trump já afirmou que não fará isso ao menos nesse momento ${ }^{22}$. Ao contrário da expectativa inicial, as negociações com a China avançaram e já houve um acordo inicial entre as partes em relação à abertura de mercado. As principais concessões da China foram as permissões para a entrada de carne dos Estados Unidos no mercado chinês e a conceder acesso ao seu mercado interno para as empresas norte-americanas de cartão de crédito. De caráter simbólico, mas relevante para a China, o documento traz o reconhecimento dos Estados Unidos da importância da nova Rota da Seda ${ }^{23}$. Evidentemente, o acordo firmado não soluciona as controvérsias comerciais entre as partes, os dois países não concordam nem mesmo sobre o valor dos fluxos de comércio e o tamanho do déficit. Em 2015, por exemplo, de acordo com a contabilidade norte-americana, o saldo a favor da China foi de 367,5 bilhões de dólares, e, segundo a contabilidade chinesa, foi de 260,9 bilhões de dólares ${ }^{24}$.

Outro compromisso para os cem primeiros dias era o início por parte da Secretaria de Comércio e do USTR (U.S. Trade Representative) de uma investigação das práticas injustas de comércio adotadas pelos parceiros norte-americanos que prejudicam os trabalhadores dos Estados Unidos. Essa 
investigação já foi determinada ${ }^{25}$. Entretanto apenas em maio, Robert Lighthizer tomou posse no cargo, pois apesar de ter sido indicado ainda no início de janeiro por Trump, a aprovação pelo Senado só ocorreu em 11 de maio. Portanto, o ritmo das mudanças nas práticas de comércio exterior está bastante lento, a própria Agenda de Política de Comércio Exterior do Presidente para 2017 foi apresentada sem a participação do USTR, assim o texto foi apresentado para cumprir a obrigação legal de fazê-lo até 01 de março, mas promete-se um mais detalhado para depois da aprovação do nome pelo Senado, que ainda não foi feito.

De um modo geral, a Agenda de Política de Comércio Exterior explicita de forma mais sofisticada a retórica de campanha de Trump em relação ao comércio internacional. O primeiro princípio é colocar a soberania nacional acima da política de comércio exterior, sobre a OMC postula "it is importante to recall also that Congress had made clear that Americans are not directly subject to WTO decisions" ${ }^{26}$.O segundo é adotar uma aplicação mais estrita da legislação de comércio exterior dos Estados Unidos para obrigar os parceiros a adotarem uma prática de comércio justa, o caminho é, como nos anos 1980, a aplicação do artigo 301 da Lei de Comércio Exterior de 1974.

Os outros dois caminhos para fazer o comércio exterior contribuir para a economia norte-americana e para o aumento do emprego seriam pressionar para abrir mercados externos e negociar novos e melhores acordos comerciais. Independente das grandes negociações comerciais e das grandes decisões, os Estados Unidos de Trump já estão tomando medidas concretas sobre casos concretos que acabam por aumentar a pressão sobre os parceiros. Foi divulgada em 11 de julho uma decisão do Departamento de Comércio dos Estados Unidos de impor uma taxa de antidumping sobre Borracha de Butadieno Estireno produzida por Brasil, Coreia do Sul, México, Polônia ${ }^{27}$. A nota à imprensa sobre o caso informa "Enforcement of U.S. trade law is a prime focus of the Trump Administration" 28 .

As medidas para os cem primeiros dias também previam a criação de uma tarifa para desestimular as empresas de fecharem unidades nos Estados Unidos e abrirem no exterior para exportar para o mercado norte-americano. No entanto, exceto pelas publicações no Twitter ameaçando as empresas que anunciavam planos de aumentar os investimentos no exterior como a Ford, a GM e a Toyota, Trump ainda não tomou nenhuma medida concreta para introduzir taxações e restrições à internacionalização das empresas norteamericanas $^{29}$. A medida encontraria grande resistência em meio às lideranças econômicas e intelectuais do Partido Republicano, cujas ideias estão fortemente baseadas nos princípios do liberalismo econômico.

Em relação ao México, Trump apresentou duas propostas, a mais polêmica e que tem chamado a atenção da mídia desde a campanha é a construção do muro ao longo de toda a fronteira, a outra é a revisão do Nafta. 
O primeiro impulso de Trump era abandonar o Nafta, a medida constava entre as metas dos primeiros 100 dias, entretanto esta posição já foi flexibilizada e substituída pela demanda de revisão do acordo ${ }^{30}$. É fato que os Estados Unidos possuem déficit comercial com o México e o Canadá, especialmente com o primeiro. No entanto, a interpretação de que o déficit comercial decorre simplesmente da saída de empresas norte-americanas dos Estados Unidos para o México em função do Nafta é equivocada. Os Estados Unidos já eram deficitários com o México e o Canadá antes do acordo.

O papel do dólar na economia mundial, a valorização ao longo dos anos 1980, e a centralidade dos Estados Unidos como cento financeiro mundial desempenham papel muito mais importante na geração do déficit comercial global dos Estados Unidos do que o acordo do Nafta. Mas ainda que seja válido argumentar que o Canadá e o México ganharam mais do que os Estados Unidos com o acordo, os ganhos norte-americanos não podem ser minimizados. Em 2016, por exemplo, os Estados Unidos exportaram para o Canadá 266,7 bilhões de dólares, para o México 229,7 bilhões, e para a China 115,6 bilhões. No mesmo ano, o déficit comercial com o Canadá foi de 10,9 bilhões, com o México foi de 64,3 bilhões, e com a China foi de 347,0 bilhões de dólares. Considerando as diferenças entre o tamanho da economia mexicana e a do Canadá e, especialmente, a da China, fica evidente a importância do México como mercado consumidor para os Estados Unidos. Uma guerra comercial seria desastrosa não apenas para o México como também para os Estados Unidos ${ }^{31}$.

Trump também já lançou o plano de reconstrução da infraestrutura, uma das metas é permitir que projetos de infraestrutura que demorariam 10 anos para serem implementados sejam concluídos em dois anos através da simplificação do marco regulatório permitindo uma maior eficiência no processo decisório. A modernização será feita com forte apoio do setor privado para reconstruir a infraestrutura urbana e realizar novos investimentos na infraestrutura rural. Os investimentos iniciais seriam de 200 bilhões de dólares podendo chegar a um trilhão ${ }^{32}$. Um dos projetos já lançados é de uma rede nacional de internet sem fio numa parceria público-privada entre a First Responder Network Authority (FirstNet) e a AT\&T, o investimento será de 26,5 bilhões de dólares ${ }^{33}$. Enquanto, anuncia projetos de infraestrutura com apoio de investimentos públicos, a proposta orçamentária de Trump reproduz a tradição dos presidentes de elevar os gastos militares e fazer cortes nos gastos sociais. No entanto, as condições políticas não permitiram que o presidente Trump inserisse a construção do muro na fronteira com o México no orçamento ${ }^{34}$.

\section{Trump e suas consequências}

A sempre citada frase de Hegel, "a coruja de Minerva alça voo ao entardecer", é bastante pertinente neste momento, só conheceremos o significado histórico do governo de Donald Trump após o encerramento 
do seu ciclo presidencial seja qual for o processo que leve a isso, o sempre especulado impeachment, a derrota eleitoral na reeleição ou conclusão normal de dois mandatos presidenciais. O que se pode atestar nesse momento é que Trump traz tanto elementos de continuidade como de ruptura com o padrão a estrutura política e econômica dos Estados Unidos desde o final da Segunda Guerra Mundial.

Do ponto de vista da economia interna, Trump expressa a visão econômica tradicional dos membros do partido Republicano, faz a defesa da redução dos impostos, especialmente dos setores mais ricos da sociedade, é crítico das políticas sociais e, assim, propõe não apenas o fim do Obamacare como a redução do gasto social em geral, e ainda da desregulamentação. Por outro lado, em alguns aspectos a agenda de Trump se distancia da retórica liberal tradicional ao enfatizar a necessidade dos investimentos estatais em infraestrutura, e de algum ativismo estatal na geração de empregos e requalificação da mão de obra. Mas mesmo estes aspectos liberais agora são apresentados dentro de uma retórica mais reacionária, como uma reação aos efeitos da globalização nos Estados Unidos.

É evidente que o processo de internacionalização do capital desde o final da Segunda Guerra Mundial favoreceu as empresas norte-americanas e aprofundaram a centralidade da economia dos Estados Unidos para a economia mundial. Entretanto, o desenvolvimento capitalismo é, por definição, um processo desigual. As novas tecnologias e a liberalização da economia ampliaram as possibilidades de deslocamento do capital pelo espaço econômico mundial. O resultado foi o desenvolvimento de certas regiões e o retrocesso em outras. Os Estados Unidos se beneficiaram desigualmente do mesmo movimento, o florescimento das empresas do Vale do Silício e o declínio das cidades da indústria automobilística como Detroit. Já nos anos 1970, Gilpin pontuava:

In contrast to the prevailing assumption that American corporate expansionism is in the larger national interest of the United States, I believe the United States must address itself to the question of the costs and benefits of foreign direct investment. As American influence declines and as foreign governments force American corporations to serve their interests, Americans must more critically examine whether corporate and national interests coincide ${ }^{35}$.

O processo de liberalização avançou sem que o Estado norte-americano considerasse os efeitos desiguais e perversos da globalização, presumiu-se que a maior competitividade e desenvolvimento tecnológico das companhias norte-americanas garantiria resultados satisfatórios também para os cidadãos. No entanto, o desenvolvimento das novas tecnologias provoca um efeito 
complexo de desqualificação periódica da mão de obra e de economia de força de trabalho no processo produtivo. As taxas de crescimento deveriam ser extremamente elevadas para compensar não apenas esses efeitos como também da transferência da produção para o exterior. O que de fato ocorreu foi um aumento da desigualdade de renda em torno da polarização entre os setores produtivos e financeiros mais dinâmicos associados à internacionalização do capital e os setores de menor competitividade, fortemente dependente do mercado nacional. A segmentação fica evidente nos setores de serviços pessoais, faz enorme diferença para a renda pessoal se o serviço de cabelereiro, ou serviços de alimentação, entre outros são ofertados para os estratos mais ricos ou não. Uma consequência é o declínio da classe média muita enfatizada no discurso de Trump.

Trump vê os efeitos do processo e não consegue compreender as causas e, por isso, suas políticas tendem a aprofundar os efeitos perversos internos e aumentar a instabilidade econômica global. No diagnóstico de Trump, o processo de globalização do capital está provocando efeitos indesejados nos Estados Unidos, porque os parceiros norte-americanos adotam práticas injustas de produção e comércio, não liberalizaram suficientemente suas economias e com isso o resultado das relações econômicas internacionais são distorcidos. Faz-se, portanto, necessário retaliar os concorrentes norte-americanos, pressioná-los para que alterem suas regras, e suas práticas comerciais devem ser julgadas a partir dos parâmetros da legislação norte-americana.

Além disso, é preciso reforçar a desregulamentação da economia interna, porque o excesso de normas está colocando barreiras ao crescimento econômico. Daí surge um nacionalismo exótico fundado na ideia de que a maior potência mundial se tornou vítima do resto do mundo. O slogan "America First" reflete a percepção de que os Estados Unidos S sacrificaram os seus interesses nacionais em favor de objetivos colocados pelo sistema internacional. Representa uma inversão do discurso dominante no resto do mundo sobre o comportamento dos Estados Unidos, nos anos 1980 as práticas comerciais norte-americanas em relação aos seus parceiros foi caracterizada como unilateralismo agressivo, e as ações norte-americanas contra o terrorismo, especialmente o ataque ao Iraque em 2003, também foram entendidas como unilaterais ${ }^{36}$.

A ascensão de Trump aponta para a dificuldade dos Estados Unidos reconstruírem a sua hegemonia no sentido gramsciano do termo. Desde os anos 1970, as bases da hegemonia norte-americana no período 1945-1970 estão sendo erodidas, e os Estados Unidos não se mostram capazes de reconstruí-las, utilizam-se de vários instrumentos para reafirmar o seu poder, a capacidade para determinar os rumos da economia e da política internacionais, mas não conseguem ir além da demonstração de força para exercer a dominação. E, mesmo mantendo a capacidade de definir unilateralmente suas políticas, os Estados Unidos não são capazes de determinar os resultados destas políticas 
nem internamente, nem internacionalmente, e os revezes acabam por aumentar a pressão sobre o próprio establishment norte-americano. Trump, no seu papel de establishment econômico e antiestablishment político, é uma síntese dessas tensões, e, isso aumenta os riscos e a imprevisibilidade de sua atuação. Nesse aspecto, a ideologia liberal e do self-made man presentes na sociedade norteamericana e representada por Trump aumentam os riscos.

No pensamento econômico liberal, especialmente na versão neoclássica, trabalha-se com a ideia de indivíduo representativo para analisar o comportamento do mercado, o resultado dessa opção teórica é que se pensa o objetivo e o comportamento dos indivíduos no mercado como sendo transparentes, o resultado é sempre a harmonia, a possibilidade de erro por parte dos agentes econômicos é descartada, eles conhecem o necessário para tomar a decisão, e o resultado do mercado expressa o esforço de cada um. Portanto, sempre que há instabilidade, desarmonia é por restrições que impedem o mercado de funcionar bem, e a solução sempre mais liberalização. Por outro lado, isso significa que nem os indivíduos nem as firmas são capazes de controlar o resultado do mercado, e obviamente nem o Estado.

Dentro dessa realidade, não é fácil ser o self-made man, no discurso de Trump, os esforços dos trabalhadores norte-americanos não estão sendo bemsucedidos pelas violações ao livre-mercado fora dos Estados Unidos, diante disso o que se espera do presidente Trump que coloca como a personificação do self-made man? Os Estados Unidos não estão em melhor situação apenas porque Obama, o establishment político em Washignton não fez o necessário para garantir a vitória norte-americana, não se esforçaram suficientemente. A disposição de Trump para provar ser capaz será uma fonte permanente de tensão na arena internacional e para a economia mundial. É preciso notar que os déficits comercial e de transações correntes dos Estados Unidos não são reversíveis sem modificações significativas no sistema monetário e financeiro internacional.

Para a América Latina, o governo de Donald Trump representará permanentemente um fator de tensão pela disposição em atacar os fluxos migratórios, o que deve acabar gerando controvérsias para as relações bilaterais na medida em que os Estados Unidos queiram cooperação dos países da região para conter os fluxos migratórios como se coloca nas declarações públicas de Trump sobre o México. Do ponto de vista econômico, o conflito em torno do Nafta com o México deve ser mantido ao longo de todo o mandato de Trump se o objetivo final for reverter o déficit comercial com o país. E dentro desta mesma estratégia, é possível conflitos comerciais com os países com os quais os Estados Unidos celebraram acordos de livre comércio, Chile e Peru, cuja presença comercial chinesa é cada vez mais notória. Desde a crise de 2008, o Brasil deixou de ter superávit comercial com os Estados Unidos para ter déficit, essa situação não deve ser revertida em médio prazo mesmo com a 
queda das importações brasileiras provenientes dos Estados Unidos por causa da crise brasileira.

Sendo assim, e considerando que Trump rejeita a negociação de novos grandes acordos de livre comércio, as relações comerciais não devem ser um ponto de conflito nas relações entre o Brasil e os Estados Unidos. E as consequências das políticas de Trump sobre o Brasil devem ser sentidas mais pelos efeitos sistêmicos das opções de política externa e comércio exterior do que por iniciativas no plano bilateral. Eventualmente, se o Brasil retomasse as condições políticas para reativar a política de liderança e integração da América do Sul, as tensões tenderiam a aumentar. Dificilmente um governo Trump estaria disposto a debater as suas políticas para os países da região com o governo brasileiro como o Departamento de Estado fez em relação às questões venezuelanas no início do governo Lula. Enfim, dada a agenda econômica de Trump, o mais provável é a maior marginalização da região na política externa norte-americana.

\section{Considerações finais}

Se dentro dos Estados Unidos, as divisões entre os republicanos, a divisão de poderes, as instituições de um modo geral podem colocar obstáculos aos planos de mudança de Trump tanto no plano econômico como político, no âmbito internacional, o unilateralismo norte-americano tende a ser bastante eficaz para definir as tendências de uma época tanto na política como na economia internacional, e, portanto, a capacidade de Trump impor a sua vontade na política externa e de comércio exterior é muito maior. Consequentemente, todo o governo Trump será marcado pela incerteza. No entanto, o presidente norte-americano não é um ator irracional, por exemplo, se o uso do Twitter continua sendo um importante instrumento de mobilização tanto da agenda política interna como para marcar posicionamentos internacionais, Trump não tem deixado de modular suas propostas às circunstâncias.

Sair do TPP ou do acordo de Paris concretizou propostas de campanha, e apesar do desgaste internacional gerado para os Estados Unidos e para Trump, mostrou aos eleitores de Trump sua disposição de colocar os interesses da economia norte-americana acima das questões internacionais. $\mathrm{O}$ custo de cumprir as promessas foi baixo. A proposta de deixar o Nafta já foi abandonada. Também abandonou a retórica agressiva em relação à China, não apenas em relação à questão de Taiwan como também nas questões comerciais. Nesse sentido, o discurso de Trump, sua retórica deverá ser um fato de instabilidade ao longo de todo período, mas é improvável que as políticas expressem linearmente essa retórica.

Trump superdimensiona o poder dos Estados Unidos para definir as características do sistema internacional, portanto, o unilateralismo deve aumentar e agravar as controvérsias internacionais em temas políticos e econômicos, 
por outro lado, o resultado não deve ser o fortalecimento dos Estados Unidos como esperado pelo presidente norte-americano, mas seu enfraquecimento. A atuação internacional dos Estados Unidos será deslegitimada. O sistema internacional não se tornará chinês em função disso, mas a China deve estender seu raio de ação, a retórica chinesa do desenvolvimento pacífico e do mundo harmonioso ganharão maior significado e consistência na contraposição ao unilateralismo norte-americano. Do ponto de vista econômico, o efeito sistêmico da liberalização e da financeirização da economia norte-americana desde os anos 1970 favoreceu o projeto chinês de desenvolvimento. Agora, o redirecionamento político dos Estados Unidos liderado por Trump pode abrir espaço para a ampliação do soft power chinês.

\section{Notas}

1 Professor do Departamento de Relações Internacionais da Universidade Federal de Sergipe. Mestre em Economia pela Unicamp. E-mail: corival@gmail.com

$2 \mathrm{O}$ documentário pode ser encontrado na íntegra aqui: https://goo.gl/1dnoyX

3 COWEN, Tyler. Whose ideas guide Trump. Bloomberg, 01/08/2016. Disponível em: https:// goo.gl/4EHF9b. Dan Kopf, em publicação no Quartz, "Trump's top economic advisors are, essentially, Democrats", afirma que além de Democrata, Navarro é um crítico de Reagan para mostrar como está distante das ideias econômicas do Partido Republicano. Disponível em: https://goo.gl/F3PymP

4 HEILBRUNN, Jacob. The most dangerous man in Trump world? How Peter Navarro could lead us into a global depression - or worse. Politico, 12/02/2017. Disponível em: https://goo. $\mathrm{gl} / \mathrm{GMgi} 8 \mathrm{~T}$

5 WILLIAMSON, Kevin D. Peter Navarro: Trump's nutty economics professor. National Review, 14/04/2017. Disponível em: https://goo.gl/1J1xKJ

6 WORSTALL, Tim. Trump admin's Peter Navarro doesn't know Econ 101 about trade. Forbes, 06/03/2017. Disponível em: https://goo.gl/GocWRB

7 Outline of Donald Trump's economic vision: winning the global competition, 2016, p.1. Disponível em: https://goo.gl/qGjB1j

8 Outline of Donald Trump's economic vision: winning the global competition, 2016, p.2. Disponível em: https://goo.gl/qGjB1j. Além desse documento é possível encontrar uma visão das propostas de Trump expressa por seus assessores: ROSS, Wilbur; PUZDER, Andy; NAVARRO, Peter. Donald Trump's contract with the American voter. 30/10/2016. Disponível em: https://goo.gl/1kT5KN

9 TRUMP, Donald. Grande outra vez: como recuperar a América debilitada. Porto Alegre, CDG, 2017, pp.69-70.

10 Outline of Donald Trump's economic vision: winning the global competition, 2016, p.4. Disponível em: https://goo.gl/qGjB1j

11 TRUMP, Donald. Grande outra vez: como recuperar a América debilitada. Porto Alegre, CDG, 2017, p.95.

12 RODRIK, Dani. Too late to compensate free trade's losers. Project Syndicate, 11/04/2017. 
Disponível em: https://goo.gl/XNL6Jp

13 FRIEDMAN, Milton; FRIEDMAN, Rose. Tirania do status quo. Rio de Janeiro, Record, 1983.

14 Após revés, Trump fala em 'simplesmente revogar' Obamacare. Folha de São Paulo, 18/07/2017. Disponível em: https://goo.gl/vtBdNp

15 Trump to Require Two Rules Be Killed for Each New One Issued. Bloomberg, 30/01/2017. Disponível em: https://goo.gl/5zvoXd

16 Trump dá sinal verde para construção de dois oleodutos criticados por ambientalistas. G1, 24/01/2017. Disponível em: https://goo.gl/5uPX5G

17 VINIK, Danny. What Trump could do to the Federal Reserve. 15/03/2017. Disponível em: https://goo.gl/QTBEvR. Outras informações sobre as propostas para o FED, a moeda e o sistema financeiro podem ser lidas em: Trump Favors Returning To The Gold Standard, Few Economists Agree. NPR, 26/06/2016. Disponível em: https://goo.gl/gJV4mg. Trump names new Fed regulatory chief. CNN, 10/07/2017. Disponível em: https://goo.gl/2SAHXv. Trump announces Quarles as top bank cop. Politico, 10/07/2017. Disponível em: https://goo.gl/BmqW9o . Trump to nominate investment fund manager Randal Quarles to key Federal Reserve post. Los Angeles Times, 11/07/2017. Disponível em: https://goo.gl/htWrHZ

18 Trump to nominate Quarles to be Fed's top banking regulator. Reuters, 10/07/2017. Disponível em: https://goo.gl/9QuBBD

19 VINIK, Danny. What Trump could do to the Federal Reserve. 15/03/2017. Disponível em: https://goo.gl/QTBEvR.

20 U.S. House committee approves bill to increase scrutiny of Fed. Reuters, 28/03/2017. Disponível em: https://goo.gl/u5ms7U

21 US_WHITE HOUSE. America First Foreign Policy. 2017. Disponível em: https://www. whitehouse.gov/america-first-foreign-policy

22 Trump Says Dollar 'Getting Too Strong,' Won't Label China a Currency Manipulator. The Wall Street Journal, 12/04/2017. Disponível em: https://goo.gl/2Hgh7h

23 US_DEPARTMENT OF COMMERCE. Initial results of the 100-Day Action Plan of the U.S.-China Comprehensive Economic Dialogue. 11/05/2017. Disponível em: https://goo.gl/ jFxmPE

24 MARTIN, Michael F. What's the difference? - Comparing U.S. and chinese trade data. Congressional Research Service Report, 2016. Disponível em: https://goo.gl/ntFZN1

25 US_WHITE HOUSE. Presidential Executive Order regarding the omnibus report on significant trade deficits. 31/03/2017. Disponível em: https://goo.gl/jTmVx8

26 USTR. 2017 Trade Policy Agenda and 2016 Annual Report of the President of the United States on Trade Agreements Program. 2017, p.3. Disponível em: https://goo.gl/zAbGv5

27 US_DEPARTMENT OF COMMERCE. Fact Sheet:Commerce Finds Dumping of Imports of Emulsion Styrene-Butadiene Rubber from Brazil, Korea, Mexico, and Poland. 11/07/2017. Disponível em: https://goo.gl/QQJT12

28 US_DEPARTMENT OF COMMERCE. U.S. Department of Commerce Issues Affirmative Final Antidumping Duty Determinations of Emulsion Styrene-Butadiene Rubber from Brazil, Korea, Mexico, and Poland. 11/07/2017. Disponível em: https://goo.gl/JQjf2j 
29 Trump's tweets keep US manufacturers on their toes. Criticism of Ford, GM and others raises prospect of elements of US industrial strategy being formulated on social media. The Guardian, 04/01/2017. Disponível em: https://goo.gl/CN6Syt

30 Trump volta atrás em proposta de sair do NAFTA. El País, 27/04/2017. Disponível em: https://goo.gl/Mq4oc7. As propostas que seriam adotadas nos primeiros 100 dias e a situação atual pode ser encontrada em: Trump's 100-Day Plan, Annotated: Where His Promises Stand. 24/04/2017. Disponível em: https://goo.gl/6nxj3X

31 Dados sobre o Canadá disponíveis em: https://goo.gl/Bm6kLG. Dados sobre o México disponíveis em: https://goo.gl/GrdozS. Dados sobre a China disponíveis em: https://goo.gl/ EtfjLT.

32 US_WHITE HOUSE. President Trump's Plan to Rebuild America's Infrastructure. 08/06/2017. Disponível em: https://goo.gl/hWN18y

33 US_DEPARTMENT OF COMMERCE. U.S. Secretary of Commerce Wilbur Ross Announces FirstNet Public-Private Partnership. 30/03/2017. Disponível em: https://goo.gl/VS$\mathrm{rHmA}$

34 AHRENS, Jan Martínez. Orçamento de Trump faz corte drástico em programas sociais: O projeto apresentado reduz os auxílios aos desfavorecidos e aumenta a fatia militar. El País Brasil, 23/05/2017. Disponível em: https://goo.gl/K9Dqcx. US_OFFICE OF MANAGEMENT AND BUDGET. Budget of the U.S. Government: a new foundation for American greatness. Fiscal Year 2018. 2017a. Disponível em: https://goo.gl/W96w72. US_OFFICE OF MANAGEMENT AND BUDGET. America First: a Budget Blueprint to make America Great Again. 2017a. Disponível em: https://goo.gl/PbkNpR. US_OFFICE OF MANAGEMENT AND BUDGET. Major Savings and Reforms: Budget of the U.S. Government, Fiscal Year 2018. Disponível em: https://goo.gl/jYZQEs. US_EXECUTIVE OFFICE OF THE PRESIDENT. Fiscal Year 2018: Congressional Budget Submission. 2017. Disponível em: https://goo.gl/kAmS3g.

35 GILPIN, Robert. U.S. power and the multinational corporation: The political economy of foreign direct investment. New York, Basic, 1975, p.7.

36 PECEQUILO, Cristina Soreanu. Os Estados Unidos e o século XXI. Rio de Janeiro, Elsevier, 2013.

Recebido em 06/04/2017

Aprovado em 22/09/2017 